\title{
Why are there so few ethnic minorities in ecology and evolutionary biology? Challenges to inclusion and the role of sense of belonging
}

\author{
Laurie T. O'Brien ${ }^{1}$ D $\cdot$ Henry L. Bart ${ }^{2} \cdot$ Donna M. Garcia ${ }^{3}$
}

Received: 1 October 2018 / Accepted: 25 November 2019 / Published online: 3 February 2020

(c) The Author(s) 2020

\begin{abstract}
African Americans and other ethnic minorities are severely underrepresented in both graduate education and among the professoriate in ecology and evolutionary biology (EEB). In the present research, we take a social psychological approach to studying inclusion by examining interrelationships among challenges to inclusion, the sense of belonging, and interest in pursuing graduate education in EEB. We conducted a survey of African American $(\mathrm{N}=360)$, Latino/a/Hispanic $(\mathrm{N}=313)$, White $(\mathrm{N}=709)$, and Asian/Asian American $(\mathrm{N}=524)$ college undergraduates majoring in science, technology, engineering, and math fields and used the results to test several interrelated hypotheses derived from our theoretical model. Compared to Whites, ethnic minorities were more likely to experience challenges to inclusion in EEB (e.g., less exposure to ecology, fewer same-race role models, discomfort in outdoor environments). Challenges to inclusion were associated with a decreased sense of belonging in EEB educational contexts. Finally, experiencing a low sense of belonging in EEB educational contexts was associated with lower interest in pursuing graduate education in EEB. Sense of belonging in EEB was especially low among African Americans relative to Whites. We discuss the implications of the study results for educational interventions.
\end{abstract}

Keywords Ecology and evolutionary biology · African Americans · Graduate education $\cdot$ Sense of belonging $\cdot$ Challenges to inclusion

Laurie T. O'Brien

lobrien2@tulane.edu

1 Department of Psychology, Tulane University, New Orleans, LA 70118, USA

2 Department of Ecology and Evolutionary Biology, Tulane University, New Orleans, LA 70118, USA

3 Department of Psychology, California State University San Bernardino, 5500 University Parkway, San Bernardino, CA 92407, USA 


\section{Introduction}

Historically, ethnic minorities have been excluded from participation in many science, technology, engineering, and math (STEM) fields and ethnic disparities in participation continue into the present day (e.g., Smith and White 2011; OECD 2006). In the U.S., STEM fields are dominated by White men and African Americans, Hispanics/Latino/a Americans, and Native Americans are recognized as underrepresented minorities (URMs) because people from these groups obtain advanced degrees in STEM fields at rates lower than their representation in the U.S. population (National Science Foundation, National Center for Science and Engineering Statistics, NSF, NCSES 2017). Systemic barriers affect the participation of URMs in STEM fields (e.g., Clotfelter et al. 2005; Riegle-Crumb and Grodsky 2010a; Young 2005). Although African Americans, Latinos/as, and Native Americans are underrepresented in STEM as a whole, there is tremendous variability across STEM fields in the representation of ethnic minorities ${ }^{1}$ (e.g., Leslie et al. 2015; NSF, NCSES 2015).

African Americans in particular are severely underrepresented in graduate programs and as faculty in departments specializing in ecology and evolutionary biology (EEB), commonly federated subdisciplines of biology dealing with how organisms interact with each other and their environment. In 2014, African Americans earned less than $1.8 \%$ of the Ph.D.'s awarded in EEB-related subfields (Ecology, Evolutionary Biology, Botany, Entomology, Marine Biology, Wildlife Biology, Zoology, NSF, NCSES 2015). During that same year, African Americans earned $5.1 \%$ of Ph.Ds. awarded in non-EEB related subfields of biology, and $6.4 \%$ of all Ph.Ds. awarded. Given that African Americans constitute 13\% of the US population, they are clearly underrepresented among all Ph.D. recipients-but, the problem is particularly severe in EEB. ${ }^{2}$

The goal of the present research is to shed light on factors that may contribute to the underrepresentation of African Americans and other ethnic minorities in EEB graduate education. We focus on interest in graduate education among college undergraduates because graduate school is a critical juncture in the higher education pipeline where students make important decisions about their disciplinary specialization and becoming academic professionals. The vitality of the EEB profession, as in any field of study, is a reflection of the diversity, professional development, interests, and worldview of the people posing questions and formulating hypotheses within the field (Armstrong et al. 2007). Evolutionary biologists and ecologists contribute to understanding and responding to some of the most serious problems

\footnotetext{
1 We use the term "ethnicity" to refer to a population group with common cultural traditions and a shared history. We use the terms African Americans, Native Americans, Latinos/as, Asians, and Whites without implying any biological significance to these designations. We use these designations because they are commonly used in U.S. culture and become socially meaningful when membership in a particular ethnic group results in differential treatment and access to resources within society (see Jones et al. 2013).

2 To our knowledge, comparable data on ethnic minority participation in EEB in countries besides the U.S. is not publically available. We return to this point in the general discussion.
} 
threatening human and other inhabitants of Earth, including climate change, emerging disease, invasive species, and consequences of loss of biological diversity. The very low rate of completion of Ph.D.'s in EEB by African Americans and other minorities has downstream consequences for the diversity of applicant pools for postdoctoral researcher and faculty positions in EEB-focused academic departments at universities, and researcher positions at federal agencies and non-governmental organizations specializing in EEB, with a concomitant effect on diversity in the EEB profession as a whole. Using a social psychological approach, we examine potential challenges to inclusion in EEB, focusing on the central role of sense of belonging in EEB and the question of whether a reduced sense of belonging in EEB is associated with lower interest in pursuing graduate education in EEB.

\subsection{Patterns of participation in STEM and EEB}

Despite having generally positive attitudes towards STEM and relatively strong intentions to major in STEM fields, URM students are less likely to complete undergraduate STEM degree requirements than White students (Riegle-Crumb and King 2010b; O’Brien et al. 2015; Young 2005; Zhang et al. 2004). Systemic differences in teacher quality, school funding, and course-taking at the high school level can leave URM students less prepared than White students for rigorous college STEM majors. African American and Latino/a students are more likely to be enrolled in high schools with lower teacher quality and less school funding compared to White students (Clotfelter et al. 2005; Ingersoll 2002). In addition, compared to White students, African American students tend to take fewer math and science courses in high school, are less likely to take AP math and science courses (which are less likely to be offered at under resourced schools), and are less likely to take costly AP math and science exams (O'Sullivan and Grigg 2001; Riegle-Crumb and King 2010b; College Board 2014). In response, many scholars have advocated for increasing institutional accountability for inequitable outcomes between URM students and White students (Bauman et al. 2005; Dowd and Bensimon 2015).

While factors such as teacher quality, school funding, and course-taking in high school provide explanations for the underrepresentation of African Americans relative to Whites among STEM majors more generally, they are unlikely to explain the variation in representation of African Americans within different STEM disciplines such as biology. For example, it is unlikely that teacher quality can fully account for the relatively lower levels of representation among African Americans obtaining Ph.D.'s in EEB (1.8\%) compared to non-EEB (5.1\%) subfields of biology. Thus, in addition to differences in preparation that result from unequal access to resources, there are likely to be other factors that influence the representation of African Americans and other minorities in EEB. STEM fields can vary tremendously in the cultures found within their field and these culture differences may affect the participation of URMs (Leslie et al. 2015). STEM fields with cultures that view success as a result of brilliance tend to have fewer minorities than STEM fields with cultures that view success as a result of hard work. In other words, STEM cultures that promote fixed theories of intelligence appear to be less welcoming to URMs than STEM 
cultures that promote malleable theories of intelligence (e.g., see also Murphy and Dweck 2010; Rattan et al. 2018). Mismatches between the cultural background of students and institutional culture can have far reaching negative consequences for students (Edman and Brazil 2009; Smith et al. 2014; Stephens et al. 2012a, b). Thus, in addition to group differences in access to resources, features of the organizational culture present in STEM fields are another factor that can promote or hinder the participation of different groups in STEM.

The pattern of participation among underrepresented groups in EEB differs from the pattern in many other STEM fields. First, STEM fields with low representation of African Americans are generally fields with low representation of women (Leslie et al. 2015). Whereas African Americans have extremely low representation in $\mathrm{EEB}$, women now outnumber men among $\mathrm{PhD}$ recipients and new tenure-track hires (Fox 2018; NSF, NCSES 2015). In 2014, women constituted 52.3\% of PhDs awarded in EEB (NSF, NCSES 2015). Second, in addition to African Americans, Latinas/os (6.6\%), Native Americans (0.2\%), and Asians (3.7\%) are all underrepresented among EEB Ph.D. recipients relative to their presence in the U.S. population. The underrepresentation of Asians in EEB is particularly surprising given their relatively high rates of participation (12.6\%) in non-EEB related subfields of biology. The pattern of representation in EEB-low representation of ethnic minorities, but relatively high representation of women-departs from many other STEM fields.

\subsection{The role of sense of belonging}

In the present research, we adopted a social psychological approach to studying the underrepresentation of ethnic minorities in EEB. We theorized that group differences in access to resources and mismatches between students and the institutional culture present in EEB leave African American students, and potentially other URM students, vulnerable to feeling a lower sense of belonging in EEB contexts compared to White students. A person's sense of belonging in a particular academic domain refers to that person's feelings of membership and acceptance in the domain (Gilbert et al. 2015; O'Brien et al. 2017; Good et al. 2012; Rattan et al. 2018; Walton and Cohen 2007). African Americans can be vulnerable to feeling uncertain about their belonging in predominantly White college-level academic environments because of their underrepresentation and experiences of exclusion at these institutions (Walton and Cohen 2007, 2011). Moreover, STEM contexts may be especially likely to undermine feelings of belonging among historically underrepresented groups (Rattan et al. 2018).

A reduced sense of belonging can have a host of negative outcomes including reduced interest, motivation, achievement, and even negative health outcomes (e.g., Cheryan et al. 2009; Good et al. 2012; Rattan et al. 2018; Walton and Carr 2012; Walton and Cohen 2007; Walton and Cohen 2011). For example, when environmental cues present in STEM contexts undermine the belonging of underrepresented groups, they can experience lower STEM course grades, less interest in STEM courses, and less interest in pursuing STEM majors. The sense of belonging is critically important to achievement and interest in STEM courses for all students 


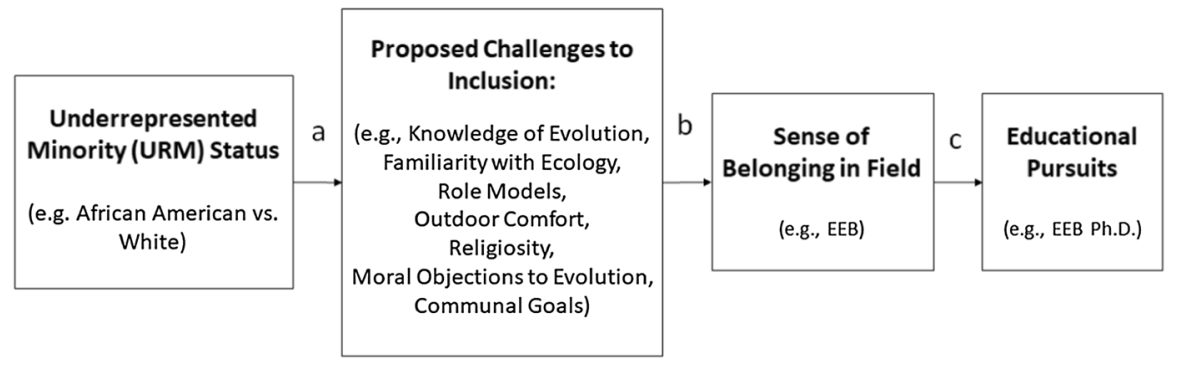

Fig. 1 Proposed theoretical model

including ethnic minorities, White women, and White men. However, features of the STEM environment are much more likely to have a negative impact on sense of belonging among members of underrepresented groups (Rattan et al. 2018; Cheryan et al. 2009). Thus, sense of belonging is an important social psychological mechanism through which features of institutional environments may lead to inequitable STEM outcomes including underrepresentation.

In the present study, we examined the role of sense of belonging in EEB contexts in predicting interest in pursuing a graduate education in EEB among an ethnically diverse sample of college students. The primary focus was on identifying factors that promote the underrepresentation of African Americans in EEB, the most extremely underrepresented group in EEB. We also included students from the other three largest ethnic groups in the U.S.: Whites, Latinos/as, and Asians. ${ }^{3}$ We hypothesized that African Americans and other ethnic minority students would be more likely than White students to experience potential challenges to inclusion resulting from factors such as inequitable access to resources (e.g., Young 2005) and a mismatch between their culture and the culture present in university EEB environments (see also Smith et al. 2014; Stephens et al. 2012a, b). In turn, potential challenges to inclusion may reduce feelings of belonging in STEM contexts. Finally, a reduced sense of belonging in EEB contexts may lower an individual's interest in pursuing a graduate education in EEB. See Fig. 1.

\subsection{Potential challenges to inclusion}

In theorizing about potential challenges to inclusion that may affect feelings of belonging in EEB contexts, we deliberately cast a wide net. First, we sought to examine potential challenges to inclusion that stem from inequitable distribution of resources (e.g., Dowd and Bensimon 2015) as well those that stem from cultural mismatches between the cultural backgrounds of students compared to organizational culture present in EEB (e.g., Stephens et al. 2012a, b). Second, we drew from the social psychological, educational, and sociological literatures on the challenges to inclusion for minorities and women in STEM fields more generally that may also

\footnotetext{
${ }_{3}$ We attempted to recruit a sample of Native American participants but were ultimately unsuccessful.
} 
affect inclusion in EEB (e.g., Dasgupta 2011; Smith et al. 2014). Finally, we sought to extend the work of past researchers who had examined the challenges to inclusion faced by ethnic minorities in EEB, many of which are unique to the EEB context (Armstrong et al. 2007; Bailey et al. 2011; Graves 2019; Mead et al. 2015).

\subsubsection{Knowledge and familiarity with EEB}

At the high school level, African American and Latino/a students are more likely than Whites to be enrolled in schools where teachers do not hold a bachelor's degree or minor in their subject area (Clotfelter et al. 2005; Ingersoll 2002). This differential access to quality teachers could potentially lead to group differences in knowledge and familiarity with EEB. There is some evidence that, compared to Whites, African Americans may have less knowledge and exposure to EEB (Mead et al. 2015). Mead et al. (2015) found that African Americans were more likely than Whites to have misconceptions about evolution; however, the finding is limited by an extremely small sample size. Moreover, the differences between Whites and other ethnic minority groups including Latinos/as, Puerto Ricans, and Native Americans were all nonsignificant, which also could be an artifact of the small sample size. Thus, additional research is needed to determine whether there are ethnic group differences in knowledge and exposure to EEB and to what extent knowledge and exposure to EEB is related to a sense of belonging in EEB contexts.

\subsubsection{Exposure to role-models}

Because ethnic minorities are underrepresented among the professoriate in EEB, most ethnic minorities will have less exposure to same-race role models than Whites (see also, Graves 2019). Role models can have a big impact on young adults' decisions to pursue a career in science (e.g., Dasgupta 2011). Most researchers have argued that ingroup role models (e.g., same-sex role models, same-race role models) are most effective for motivating student interest in STEM careers (e.g., Dasgupta 2011; Marx and Roman 2002; Marx and Goff 2005). In contrast, Drury et al. (2011) have suggested that role models do not need to be of the same gender as the student to have a positive impact. To date, the role model literature in STEM has primarily focused on women and thus less in known about the importance of same-race role models for the success of ethnic minorities (see Chemers et al. 2011; Syed et al. 2011 for exceptions). In the present research, we examined exposure to role models and the relationship between exposure to role models and a sense of belonging in EEB.

\subsubsection{Access to outdoor recreation and comfort outdoors}

Early life experiences with nature and outdoor environments may play a role in shaping interest in EEB professions. EEB often requires interaction with organisms in natural environments; consequently, college students who had outdoor exposure early in life might be more attracted to EEB relative to those students who were not afforded similar exposure. A case study of African American students participating 
in the Ecological Society of America's Strategies for Ecology Education, Development, and Sustainability (SEEDS) program revealed that $92 \%$ reported exposure to the natural environment at a young age (Armstrong et al. 2007). African Americans are less likely than White and Latino/a Americans to have opportunities to spend time as children engaged in outdoor activities such as swimming, wildlife viewing, hiking, camping, and fishing (Larson et al. 2011). In addition, African Americans are less likely than Whites to visit national parks and forests for many reasons including ease of access and concerns about safety or discrimination (Cordell et al. 1990; Cordell et al. 2004; Floyd 1998; Krymkowski et al. 2014; Solop et al. 2003; Taylor et al. 2011). These group differences in outdoor recreation access could lead to group differences in comfort in outdoor environments which, in turn, could affect feelings of belonging in EEB.

\subsubsection{Religious belief as a source of cultural mismatch}

Religious beliefs may serve as a potential source of a cultural mismatch that can affect the sense of belonging in EEB contexts. While the majority of Americans believe in God (Gallup 2016; Gervais and Najle 2018; Pew 2018), the percentage of scientists who believe in God is much smaller (Pew 2009a). Moreover, with vocal religious critics like Richard Dawkins, evolutionary biologists in particular may be perceived as hostile to religious belief (Dawkins 2006). African Americans are significantly more religious than many other American ethnic groups, overwhelmingly identifying as Protestant Christian (Pew 2009b). Thus, African Americans may be more likely than Whites to experience a real or perceived religious difference with their EEB faculty members that could affect their feelings of comfort in EEB contexts.

There is some evidence that religiosity may function as a challenge to inclusion in EEB (Bailey et al. 2011; Mead et al. 2015). Religiosity is negatively associated with exposure to evolutionary theory, knowledge about evolution, and acceptance of evolution (Hawley et al. 2011; Rissler et al. 2014). In a sample of African American college students, Bailey et al. (2011) found that the more religious students were, the less knowledge they had of evolution (see also Mead et al. 2015). Moreover, religiosity is also associated with having moral objections to the theory of evolution (Hawley et al. 2011). Thus the cultural mismatch between the religious beliefs of students and those of EEB faculty who are not generally trained to navigate religious differences and moral objections to evolution may create a challenge for inclusion that leads to lower sense of belonging in EEB contexts.

\subsubsection{Communal values as a source of cultural mismatch}

Cultural mismatches between students' values and the perceived goals afforded by a career in STEM may also be a challenge to inclusion in STEM (Brown et al. 2015; Diekman et al. 2017; Fuesting et al. 2017; Smith et al. 2014). Careers in STEM are frequently perceived by students as affording individualistic goals such as achievement and power, but not as affording communal goals such as helping others and serving the community. For students from a 
communally-oriented culture who endorse communal goals, this disconnect between their own goals and the perceived goal affordances of a career in STEM can reduce motivation to pursue a career in STEM (Smith et al. 2014; see also Diekman et al. 2017). For example, Native American college students with strong communal values who were pursuing STEM careers felt a reduced sense of belonging, reduced motivation, and reduced intentions to persist in STEM relative to Native American college students with weaker communal values (Smith et al. 2014). Although Native Americans also strongly endorsed individualistic goals, individualistic goals were unrelated to STEM outcomes among Native Americans.

One possible explanation for the low representation of ethnic minorities in EEB is that they tend to endorse communal goals and this focus may create a mismatch between the goals that students believe are afforded by a career in EEB and their personal goals. Although we are unaware of any direct test of this hypothesis in EEB, there is evidence that African Americans, Latinas/os, and Asians all tend to have strong communal values (e.g., Oyserman et al. 2002). In the present research, we examine whether a communal goal orientation can serve as a challenge to inclusion in EEB that lowers students' sense of belonging.

\subsection{Overview}

We conducted an online survey of college undergraduates majoring in STEM disciplines in order to test several hypotheses about ethnic differences in experiencing potential challenges to inclusion in EEB, the relationship between potential challenges to inclusion in EEB and sense of belonging, and, finally, the relationship between a sense of belonging and interest in pursuing a graduate degree in EEB. We examined the role of challenges to inclusion that were relatively specific to EEB (e.g., comfort outdoors) and whether known STEM-inhibiting factors (e.g., exposure to role models) were also relevant in EEB. Although our primary focus was in identifying the factors that may promote the underrepresentation of African Americans in EEB, we included students from the four largest ethnic groups in the United States: Whites, African Americans, Latinos/ as, and Asians. The inclusion of the four groups provided the ability to identify challenges that might be especially relevant or unique to African Americans. Of note, African Americans, Latinos/as, and Asians are all underrepresented among EEB Ph.D. recipients although to varying degrees.

Based on our theoretical framework and the available literature, we generated several hypotheses about group differences in the experiences of African Americans and Whites that may help to explain the underrepresentation of African Americans in EEB. The comparisons between other ethnic minorities and Whites were more exploratory. In addition, we also generated hypotheses about the relationship between challenges to inclusion and sense of belonging, and between sense of belonging and interest in graduate school that we expected to hold across all ethnic groups. 


\subsubsection{Hypothesis 1}

Relative to Whites, African Americans will be more likely to experience challenges to inclusion in EEB contexts. We examined several potential challenges to inclusion including knowledge of evolution, exposure to ecology, exposure to EEB role models, exposure to same-race EEB role models, comfort in the outdoors, religiosity, moral objections to evolution, and communal goals.

\subsubsection{Hypothesis $2 \mathrm{~A}$}

Relative to Whites, African Americans will feel a lower sense of belonging in EEB.

\subsubsection{Hypothesis 2B}

Regardless of an individual's ethnic background, the potential challenges to inclusion in EEB will be related to sense of belonging in EEB. That is, knowledge of evolution, exposure to ecology, comfort in the outdoors, and exposure to role models (in general or of the same race) will be positively associated with a sense of belonging in EEB. In comparison, religiosity, moral objections to evolution, and communal goals will be negatively related to sense of belonging in EEB.

\subsubsection{Hypothesis $3 \mathrm{~A}$}

Relative to Whites, African Americans will report less interest in graduate school in EEB.

\subsubsection{Hypothesis 3B}

Regardless of an individual's ethnic background, sense of belonging in EEB will predict interest in graduate school in EEB.

\section{Method}

\subsection{Participants}

There were 2213 participants who consented to be in the study. We retained the data from 2181 participants $(98.6 \%)$ who completed at least one relevant study measure. Degrees of freedom vary across analyses due to missing data. The present paper focuses on 1906 monoracial college students from the four largest ethnic groups in the U.S.: African Americans $(\mathrm{N}=360)$, Latinos/as/Hispanics $(\mathrm{N}=313)$, Whites $(\mathrm{N}=709)$, and Asian/Asian Americans $(\mathrm{N}=524)$. Native Americans $(\mathrm{N}=46)$ were not included in the present analyses due to insufficient sample size. In addition, multiracial $(\mathrm{N}=229)$ individuals were not included in the current analyses because of ambiguity about how to best categorize these individuals (e.g., White-Asian biracial individuals likely have very different experiences in EEB than Black-Latino biracial 
Table 1 Demographic characteristics of the sample

\begin{tabular}{lccccc}
\hline & African American & Latina/o & White & Asian & All \\
\hline Age & $20.93_{\mathrm{a}}$ & $20.71_{\mathrm{ab}}$ & $20.47_{\mathrm{b}}$ & $20.45_{\mathrm{b}}$ & 20.59 \\
Income & $4.25_{\mathrm{a}}$ & $4.34_{\mathrm{a}}$ & $5.63_{\mathrm{c}}$ & $5.17_{\mathrm{b}}$ & 5.04 \\
$\%$ Female & $54.0_{\mathrm{a}}$ & $53.9_{\mathrm{ab}}$ & $65.8_{\mathrm{c}}$ & $63.2_{\mathrm{bc}}$ & 61.0 \\
$\%$ 1 st year & $30.4_{\mathrm{a}}$ & $32.8_{\mathrm{a}}$ & $27.0_{\mathrm{a}}$ & $28.6_{\mathrm{a}}$ & 29.0 \\
$\%$ US citizen & $95.2_{\mathrm{a}}$ & $93.9_{\mathrm{a}}$ & $98.4_{\mathrm{a}}$ & $81.3_{\mathrm{b}}$ & 92.4 \\
$\%$ 1st generation & $36.4_{\mathrm{b}}$ & $55.9_{\mathrm{c}}$ & $25.7_{\mathrm{a}}$ & $33.0_{\mathrm{b}}$ & 34.7 \\
$\%$ Full-time status & $77.6_{\mathrm{a}}$ & $66.8_{\mathrm{a}}$ & $84.4_{\mathrm{b}}$ & $88.1_{\mathrm{b}}$ & 82.1 \\
$\%$ Biology majors & $33.1_{\mathrm{a}}$ & $27.2_{\mathrm{a}}$ & $33.1_{\mathrm{a}}$ & $34.7_{\mathrm{a}}$ & 32.6 \\
$\%$ Ecology classes & $56.9_{\mathrm{a}}$ & $54.5_{\mathrm{a}}$ & $52.2_{\mathrm{a}}$ & $53.1_{\mathrm{a}}$ & 53.7 \\
\% Evolutionary Bio classes & $56.6_{\mathrm{a}}$ & $54.2_{\mathrm{a}}$ & $54.1_{\mathrm{a}}$ & $57.7_{\mathrm{a}}$ & 55.5 \\
\hline
\end{tabular}

Income was measured on a Likert-type scale. Numbers within the same row that do not share the same subscript differ at $p<0.05$. All statistics are based only the participants who responded to each question and do not include missing data

individuals and thus it may not be appropriate to categorize them in one superordinate "multiracial" category). The sample included individuals from all 50 states, plus the District of Columbia and Puerto Rico. Participants' average age was 20.59 $(S D=1.92) ; 61 \%$ identified as female, $38 \%$ identified as male, and $1 \%$ identified as transgender or other. Only participants who indicated that they intended to major in a STEM field were eligible to participate; of these, biology was the most commonly listed major (32.6\%). Over half of participants reported having taken at least one class in ecology (53.7\%) and in evolutionary biology $(55.5 \%)$. The proportion of students majoring in biology and that reported taking ecology and evolutionary biology courses did not vary across participants from different ethnic backgrounds, all $p s>0.13$. See Table 1 for additional demographic information in aggregate form and broken down by ethnicity.

\subsection{Procedure}

Ethical approval for the study was obtained from the university Institutional Review Board. We contracted with Qualtrics Panels to recruit an online sample to take the survey. We originally sought to recruit 300 individuals from each of the following ethnic groups: African Americans, Latinos/as, Whites, and Asians, along with 150 Native Americans. In addition to belonging to one of these five ethnic groups, participants also needed to be between 18-26 years old, currently working on an undergraduate degree at a college or university, and planning to major in a STEM field in order to qualify for participation in the study. Qualtrics Panels encountered difficulty recruiting Native Americans and therefore we terminated the survey before reaching our desired Native American sample size. We surpassed our recruitment goals for all other ethnic groups.

Participants viewed an online consent form prior to starting the study. The consent form informed participants that the goals of the study were to assess their 
interest in pursuing different academic disciplines. After participants consented to participate, they completed the study measures in a randomized order. Once participants had completed the key study measures, they completed additional demographic information. Participants who completed the study received the equivalent of \$3 in compensation from Qualtrics Panels for their time. The research team had no way to connect participant responses to their identity and thus participant responses were anonymous.

\subsection{Measures}

Unless indicated otherwise, participants responded to all study measures by indicating their agreement on a 0-6 Likert-type scale with end points labeled "Strongly Disagree" and "Strongly Agree." To calculate participants' scores on each measure, we reverse coded items where appropriate, and averaged their responses across items. $^{4}$

\subsubsection{Challenges to inclusion}

2.3.1.1 Evolutionary knowledge We assessed evolutionary knowledge (e.g., "Mutations can be passed down to the next generation," $\alpha=0.64$ ) with four items adapted from the Evolutionary Attitudes and Literacy Survey (EALS; Hawley et al. 2011).

2.3.1.2 Exposure to ecology We assessed participants' exposure to ecology with five items (e.g., "Ecology is a subdiscipline of biological science," $\alpha=0.80$ ).

2.3.1.3 Role models In order to gauge how much exposure participants had to role models in EEB, participants answered three questions (e.g., "How many professors could you name in the fields of ecology and/or evolutionary biology?" $\alpha=0.70$ ). Participants responded on a 0-4 Likert-type scale where 0 was labeled "none" and 4 was labeled "4 or more."

2.3.1.4 Same-race role models Following each question about role models, participants were immediately asked a follow-up question about how many of the professionals they knew in EEB were from a similar racial/ethnic background as themselves. They responded using the same scale as the role-model questions $(\alpha=0.79)$.

\footnotetext{
${ }^{4}$ In addition to the measures reported here, we also assessed participants' knowledge of graduate school funding mechanisms, misconceptions about evolution, their interest in handling or harming vertebrate or invertebrate animals, their perceptions of the prestige and their interest in various subdisciplines of biology, their perceptions of careers in ecology and evolutionary biology, and their perceptions of ideal characteristics of jobs. We decided to limit the scope of the current paper to the measures reported here for various reasons including problems with reliability of some of these measures and the fact that some of these measures were single items. Please contact the authors for additional information about these measures.
} 
2.3.1.5 Outdoor comfort We assessed participants' comfort in outdoor environments with 10 items (e.g., "I enjoy spending extended amounts of time in the outdoors," $\alpha=0.77)$.

2.3.1.6 Religiosity We assessed religiosity with three items that measured frequency of religious attendance, perceived importance of faith in daily life, and perceived influence of religion in daily decision making (e.g., "How much does religion influence your daily decision making?," $\alpha=0.88$ ) All three items were assessed on a 0-6 point Likert-type scales and higher scores indicated greater religiosity.

2.3.1.7 Moral objections to evolution We assessed moral objections to evolution (e.g., "People who accept evolution as fact are immoral," $\alpha=0.84$ ) with three items adapted from EALS (Hawley et al. 2011).

2.3.1.8 Communal goals We assessed participants' endorsement of communal goals by asking them to rate the importance of six different communal goals (e.g., helping others, serving humanity; see Diekman et al. 2010). Participants rated each goal on a 0-6 Likert-type scale with end points labeled "Not at all Important" and "Very Important." Participants' ratings of the six items were averaged to create communal goal measure $(\alpha=0.74){ }^{5}$

\subsubsection{Sense of belonging in field}

2.3.2.1 Belonging in evolutionary biology We assessed participants' feelings of belonging in evolutionary biology with five items adapted from Walton and Cohen (2007) and Good et al. (2012) (e.g., "I would feel like I belong in an evolutionary biology class," $\alpha=0.78$ ).

2.3.2.2 Belonging in ecology We assessed participants' feelings of belonging in ecology with the same five items as belonging in evolutionary biology except that we replaced the words "evolutionary biology" with "ecology." $(\alpha=0.76)$.

2.3.2.3 Belonging in college We assessed participants' general feelings of belonging in college with five items $(\alpha=0.75)$ adapted from Walton and Cohen (2007; e.g., "I feel I belong in my college classes").

\subsubsection{Educational pursuits}

2.3.3.1 Interest in evolutionary biology graduate programs We assessed participants' interest in graduate programs in evolutionary biology with five items (e.g., "I would find it interesting to attend graduate school in evolutionary biology," $\alpha=0.88$ ).

\footnotetext{
5 We also assessed endorsement of individualistic goals because it is part of the measure used by Diekman and colleagues. However, we did not have hypotheses about this measure. Additional analyses revealed it did not predict the outcome variables. Therefore, we did not include it in the present analyses.
} 
Table 2 ANOVA table of ethnic differences in proposed challenges to inclusion

\begin{tabular}{lrll}
\hline & $F$ & $p$ & $\eta^{2}$ \\
\hline Knowledge of Evolution & 3.65 & 0.012 & 0.01 \\
Familiarity with Ecology & 4.22 & 0.006 & 0.01 \\
Role Models & 3.03 & 0.028 & 0.01 \\
Same-race Role Models & 102.47 & 0.001 & 0.15 \\
Outdoor Comfort & 34.94 & 0.001 & 0.06 \\
Religiosity & 39.58 & 0.001 & 0.06 \\
Moral Objections to Evolution & 34.16 & 0.001 & 0.06 \\
Communal Goals & 10.63 & 0.001 & 0.02 \\
\hline
\end{tabular}

$p<0.001$ rounded to 0.001

Table 3 Ethnic differences in proposed challenges to inclusion

\begin{tabular}{llllll}
\hline & African American & Latina/o & White & Asian & All \\
\hline Knowledge of Evolution & $4.19_{\mathrm{ab}}$ & $4.17_{\mathrm{a}}$ & $4.36_{\mathrm{b}}$ & $4.28_{\mathrm{ab}}$ & 4.28 \\
Exposure to Ecology & $4.25_{\mathrm{a}}$ & $4.31_{\mathrm{ab}}$ & $4.47_{\mathrm{b}}$ & $4.35_{\mathrm{ab}}$ & 4.37 \\
Role Models & $1.55_{\mathrm{ab}}$ & $1.58_{\mathrm{ab}}$ & $1.65_{\mathrm{b}}$ & $1.48_{\mathrm{a}}$ & 1.57 \\
Same-race Role Models & $0.90_{\mathrm{b}}$ & $0.80_{\mathrm{b}}$ & $1.45_{\mathrm{c}}$ & $0.54_{\mathrm{a}}$ & 0.99 \\
Outdoor Comfort & $3.57_{\mathrm{ab}}$ & $3.75_{\mathrm{b}}$ & $4.04_{\mathrm{c}}$ & $3.48_{\mathrm{a}}$ & 3.75 \\
Religiosity & $3.66_{\mathrm{a}}$ & $2.50_{\mathrm{b}}$ & $2.38_{\mathrm{b}}$ & $2.48_{\mathrm{b}}$ & 2.66 \\
Moral Objections to Evolution & $2.69_{\mathrm{a}}$ & $2.00_{\mathrm{b}}$ & $1.56_{\mathrm{c}}$ & $1.81_{\mathrm{bc}}$ & 1.91 \\
Communal Goals & $4.63_{\mathrm{a}}$ & $4.59_{\mathrm{ab}}$ & $4.29_{\mathrm{c}}$ & $4.43_{\mathrm{bc}}$ & 4.44 \\
\hline
\end{tabular}

Means within the same row that do not share the same subscript differ at $p<0.05$

2.3.3.2 Interest in ecology graduate programs We assessed participants' interest in graduate programs in ecology with five items (e.g., "I would find it interesting to attend graduate school in ecology," $\alpha=0.88$ ).

\section{Results}

\subsection{Challenges to Inclusion}

Hypothesis 1 focused on the differences between African Americans and Whites. We expected that African Americans would report experiencing more potential challenges to inclusion in EEB than Whites. In order to test Hypothesis 1, we conducted a multivariate analysis of variance in which the proposed challenges to inclusion were the dependent measures and ethnicity was a between-subjects variable. This analysis was highly significant, $V=0.36, F(24,5292)=30.30$, $p<0.001, \eta^{2}=0.12$. Next, we conducted univariate ANOVAs to determine which of the proposed challenges to inclusion revealed significant ethnic differences. 
All of the proposed challenges to inclusion showed statistically significant ethnic group differences. We conducted posthoc tests in order to determine which ethnic groups showed statistically significant differences. See Tables 2 and 3.

Consistent with Hypothesis 1, compared to Whites, African Americans reported less exposure to ecology, less comfort in outdoor environments, fewer same-race role models, greater religiosity, more moral objections to evolution, and more communal goals. African Americans also had less knowledge of evolution than Whites, but this difference did not quite achieve statistical significance $(p=0.060)$. Finally, there were no differences between African Americans and Whites in exposure to role models of any race. Thus, with a few caveats, there was strong support for Hypothesis 1 - that African Americans would experience more potential challenges to inclusion in EEB than Whites.

Because Latinos/as are also underrepresented in EEB relative to Whites, we also compared these groups. However, these analyses were more exploratory in nature. Compared to Whites, Latinos/as reported less knowledge of evolution, less comfort in outdoor environments, fewer same-race role models, more moral objections to evolution, and more communal goals. However, Latinos/as did not differ from Whites in their exposure to ecology, exposure to role models of any race, or in religiosity. Thus, Latinos/as reported many, but not all, of the same potential challenges to inclusion in EEB as African Americans.

Finally, because Asians are underrepresented in EEB compared to Whites (an anomaly among STEM fields), we also compared the responses of Asians to Whites. Asians reported less exposure to role models of any race and less exposure to same race role models, and less comfort outdoors. However, Asians did not differ from Whites in their knowledge of evolution, exposure to ecology, religiosity, moral objections to evolution, or communal goals. Thus, Asians reported some, but not all, of the same potential challenges to inclusion in EEB as African Americans.

\subsection{Sense of Belonging}

There were two primary hypotheses with regards to sense of belonging. First, we expected that African Americans would report lower sense of belonging in EEB relative to Whites (Hypothesis 2A). Second, we expected that challenges to inclusion would predict sense of belonging across individuals regardless of their ethnic backgrounds (Hypothesis 2B). In order to test Hypothesis 2, we conducted hierarchical regression analyses. On the first step, we entered ethnicity along with several relevant covariates (e.g., college major). This allowed us to first explore whether there were any differences between African Americans and Whites in sense of belonging. On the second step, we entered the proposed challenges to inclusion. This allowed us to examine the relationship between challenges to inclusion and sense of belonging, controlling for ethnicity and the covariates. 
Table 4 Predictors of sense of belonging in evolutionary biology

\begin{tabular}{|c|c|c|c|c|}
\hline & $r$ & $\beta$ & $t$ & $p$ \\
\hline \multicolumn{5}{|c|}{ Step 1: $R^{2}=0.20, F(6,1726)=71.70, p<0.001$} \\
\hline African American versus White & $-0.10^{* *}$ & $-0.10 * *$ & -4.08 & 0.001 \\
\hline Latino/a versus White & -0.01 & -0.023 & -0.97 & 0.331 \\
\hline Asian versus White & -0.02 & -0.023 & -0.96 & 0.337 \\
\hline Biology Major & $0.18 * *$ & $0.13 * *$ & 5.97 & 0.001 \\
\hline Evolutionary Biology Courses & $0.23 * *$ & $0.20 * *$ & 9.22 & 0.001 \\
\hline College Belonging & $0.35 * *$ & $0.34 * *$ & 15.60 & 0.001 \\
\hline \multicolumn{5}{|c|}{ Step 2: $\Delta \mathrm{R}^{2}=0.19 F(8,1718)=65.49, p<0.001$} \\
\hline African American versus White & $-0.10 * *$ & 0.04 & 1.70 & 0.090 \\
\hline Latino/a versus White & -0.01 & 0.02 & 0.90 & 0.367 \\
\hline Asian versus White & -0.02 & 0.05 & 1.83 & 0.068 \\
\hline Biology Major & $0.18 * *$ & $0.05^{*}$ & 2.32 & 0.020 \\
\hline Evolutionary Biology Courses & $0.23 * *$ & $0.14 * *$ & 6.43 & 0.001 \\
\hline College Belonging & $0.35 * *$ & $0.20 * *$ & 9.38 & 0.001 \\
\hline Knowledge of Evolution & $0.32 * *$ & $0.12 * *$ & 5.42 & 0.001 \\
\hline Exposure to Ecology & $0.29 * *$ & $0.05 *$ & 2.15 & 0.032 \\
\hline Role Models & $0.32 * *$ & $0.15 * *$ & 5.41 & 0.001 \\
\hline Same-race Role Models & $0.17 * *$ & 0.01 & 0.26 & 0.792 \\
\hline Outdoor Comfort & $0.38 * *$ & $0.20 * *$ & 9.15 & 0.001 \\
\hline Religiosity & $-0.22 * *$ & $-0.17 * *$ & -7.91 & 0.001 \\
\hline Moral Objections to Evolution & $-0.32 * *$ & $-0.20 * *$ & -8.91 & 0.001 \\
\hline Communal Goals & $0.11 * *$ & 0.02 & 0.83 & 0.409 \\
\hline
\end{tabular}

Table provides information on the Pearson $r$ (zero order) correlation between each predictor variable and sense of belonging in evolutionary biology, standardized regression coefficients, and the test of significance for each regression coefficient. $* p<0.05, * * p<0.001$

\subsubsection{Sense of belonging in evolutionary biology}

Ethnicity was dummy coded into three separate variables that compared African Americans $(+1)$ to Whites $(0)$, Latinos/as $(+1)$ to Whites $(0)$, and Asians $(+1)$ to Whites $(0)$. On Step 1, we entered the dummy coded ethnicity variables along with several proposed covariates including the general sense of belonging in college, whether or not students were biology majors, and the number of evolutionary biology courses participants had taken. Step 1 was significant, $R^{2}=0.20, F(6$, 1726) $=71.70, p<0.001$. See Table 4. Consistent with Hypothesis 2A, African Americans had a significantly lower sense of belonging in evolutionary biology as compared to Whites. The other two ethnic groups did not differ from Whites. In addition, all three of the covariates were significant.

On Step 2, we entered all of the proposed challenges to inclusion, $\Delta R^{2}=0.19, F$ $(8,1718)=65.49, p<0.001$. Consistent with Hypothesis $2 \mathrm{~B}$, the more participants were knowledgeable about evolution, had exposure to ecology, had role models of any race, and were comfortable outdoors, the more they felt a sense of belonging 
Table 5 Predictors of sense of belonging in ecology

\begin{tabular}{|c|c|c|c|c|}
\hline & $r$ & $\beta$ & $t$ & $p$ \\
\hline \multicolumn{5}{|c|}{ Step 1: $R^{2}=0.24, F(6,1736)=88.79, p<0.001$} \\
\hline African American versus White & $-0.06^{* *}$ & $-0.07 *$ & -3.20 & 0.001 \\
\hline Latino/a versus White & -0.02 & -0.04 & -1.81 & 0.070 \\
\hline Asian versus White & $-0.05^{*}$ & -0.04 & -1.79 & 0.073 \\
\hline Biology Major & $0.18 * *$ & $0.13 * *$ & 6.04 & 0.001 \\
\hline Ecology Courses & $0.26 * *$ & $0.24 * *$ & 11.45 & 0.001 \\
\hline College Belonging & $0.38 * *$ & $0.37 * *$ & 17.40 & 0.001 \\
\hline \multicolumn{5}{|c|}{ Step 2: $\Delta \mathrm{R}^{2}=0.15 F(8,1728)=52.60, p<0.001$} \\
\hline African American versus White & $-0.06^{* *}$ & 0.03 & 1.28 & 0.200 \\
\hline Latino/a versus White & -0.02 & 0.00 & 0.01 & 0.990 \\
\hline Asian versus White & $-0.05 *$ & 0.03 & 1.08 & 0.280 \\
\hline Biology Major & $0.18 * *$ & $0.06^{*}$ & 2.80 & 0.005 \\
\hline Ecology Courses & $0.26^{* *}$ & $0.16^{* *}$ & 7.35 & 0.001 \\
\hline College Belonging & $0.38 * *$ & $0.22 * *$ & 10.29 & 0.001 \\
\hline Knowledge of Evolution & $0.27 * *$ & $0.05^{*}$ & 2.24 & 0.025 \\
\hline Exposure to Ecology & $0.34 * *$ & $0.12^{* *}$ & 5.21 & 0.001 \\
\hline Role Models & $0.32 * *$ & $0.11 * *$ & 3.87 & 0.001 \\
\hline Same-race Role Models & $0.19 * *$ & -0.004 & -0.15 & 0.878 \\
\hline Outdoor Comfort & $0.47 * *$ & $0.29 * *$ & 12.96 & 0.001 \\
\hline Religiosity & $-0.08 * *$ & $-0.06^{*}$ & -2.84 & 0.005 \\
\hline Moral Objections to Evolution & $-0.21 * *$ & $-0.13^{* *}$ & -5.59 & 0.001 \\
\hline Communal Goals & $0.17 * *$ & -0.01 & -0.21 & 0.838 \\
\hline
\end{tabular}

Table provides information on the Pearson $r$ (zero order) correlation between each predictor variable and sense of belonging in ecology, standardized regression coefficients, and the test of significance for each regression coefficient. $* p<0.05, * * p<0.001$

in evolutionary biology. Also consistent with Hypothesis 2B, greater religiosity and moral objections to evolution were associated with feeling a lower sense of belonging in evolutionary biology. Finally, two findings failed to support Hypothesis $2 \mathrm{~B}$-same-race role models and communal goals were both unrelated to sense of belonging in evolutionary biology. Of note, the group difference between African Americans and Whites in sense of belonging was no longer significant once the challenges to inclusion were included in the model.

\subsubsection{Sense of belonging in ecology}

We conducted an identical hierarchical multiple regression analysis in which sense of belonging in ecology was the criterion variable. On Step 1, we entered ethnicity along with the proposed covariates (general sense of belonging in college, whether or not students were biology majors, and the number of ecology courses participants had taken), $R^{2}=0.24, F(6,1736)=88.79, p<0.001$. See Table 5. Consistent with Hypothesis 2A, African Americans had a significantly lower sense of belonging in 
ecology as compared to Whites. The other two ethnic groups did not differ from Whites. All three of the covariates were significant.

On Step 2, we entered all of the proposed challenges to inclusion, $\Delta R^{2}=0.15, F$ $(8,1728)=52.60, p<0.001$. Consistent with Hypothesis $2 \mathrm{~B}$, the more participants were knowledgeable about evolution, had exposure to ecology, had role models of any race, and were comfortable outdoors, the more they felt a sense of belonging in ecology. Also consistent with Hypothesis 2B, greater religiosity and moral objections to evolution were associated with feeling a lower sense of belonging in ecology. Finally, two findings failed to support Hypothesis 2B-same-race role models and communal goals were both unrelated to sense of belonging in ecology. Once again, the group difference between African Americans and Whites in sense of belonging was no longer significant once the challenges to inclusion were included in the model.

\subsection{Educational pursuits}

There were two primary hypotheses regarding educational pursuits. First, we expected that African Americans would report less interest in graduate school in EEB relative to Whites (Hypothesis 3A). Second, we expected that sense of belonging in EEB would predict interest in graduate school across individuals regardless of their ethnic backgrounds and after accounting for challenges to inclusion (Hypothesis 3B). In order to test Hypothesis 3, we conducted hierarchical regression analyses. On the first step, we entered ethnicity along with several relevant covariates (e.g., college major). This allowed us to first explore whether there were any differences between African Americans and Whites in interest in graduate school. On the second step, we entered the proposed challenges to inclusion and sense of belonging. This allowed us to examine the relationship between sense of belonging and interest in graduate school controlling for challenges to inclusion, ethnicity, and the covariates.

\subsubsection{Graduate school in evolutionary biology}

On Step 1, we entered ethnicity along with the proposed covariates (whether or not students were biology majors, and the number of ecology courses participants had taken), $R^{2}=0.19, F(5,1724)=81.19, p<0.001$. See Table 6 . Contrary to Hypothesis 3A, African Americans expressed more interest in graduate school in evolutionary biology as compared to Whites. Latinos/as also expressed more interest in graduate school compared to Whites whereas Asians did not differ from Whites. In addition to these ethnic differences, both of the proposed covariates were significant.

On Step 2, we entered all of the proposed challenges to inclusion along with sense of belonging in evolutionary biology, $\Delta R^{2}=0.27, F(9,1715)=97.31, p<0.001$. At Step 2, consistent with Hypothesis 3B, sense of belonging in evolutionary biology emerged as a strong predictor of interest in graduate school even with all of the other predictors in the model. In addition, several of the challenges to inclusion also predicted interest in graduate school. For example, individuals who reported more 
Table 6 Predictors of interest in evolutionary biology graduate school

\begin{tabular}{|c|c|c|c|c|}
\hline & $r$ & $\beta$ & $t$ & $p$ \\
\hline \multicolumn{5}{|c|}{ Step 1: $R^{2}=0.19, F(5,1724)=81.19, p<0.001$} \\
\hline African American versus White & $0.10^{* *}$ & $0.10^{* * *}$ & 4.15 & 0.001 \\
\hline Latino/a versus White & $0.06^{*}$ & $0.08^{*}$ & 3.27 & 0.001 \\
\hline Asian versus White & $-0.07 *$ & $-0.03 * *$ & -1.36 & 0.175 \\
\hline Biology Major & $0.14 * *$ & $0.06^{*}$ & 2.58 & 0.010 \\
\hline Evolutionary Biology Courses & $0.41 * *$ & $0.40 * *$ & 18.11 & 0.001 \\
\hline \multicolumn{5}{|c|}{ Step 2: $\Delta \mathrm{R}^{2}=0.27 F(9,1715)=97.31, p<0.001$} \\
\hline African American versus White & $0.10^{* *}$ & $0.10^{*}$ & 4.41 & 0.001 \\
\hline Latino/a versus White & $0.06^{*}$ & $0.10^{*}$ & 4.74 & 0.001 \\
\hline Asian versus White & $-0.07 *$ & $0.05^{*}$ & 2.16 & 0.031 \\
\hline Biology Major & $0.14 * *$ & $0.06^{*}$ & 2.94 & 0.003 \\
\hline Evolutionary Biology Courses & $0.41 * *$ & $0.21 * *$ & 10.20 & 0.001 \\
\hline Knowledge of Evolution & $0.14 * *$ & 0.001 & 0.07 & 0.947 \\
\hline Exposure to Ecology & $0.15^{* *}$ & 0.003 & 0.16 & 0.876 \\
\hline Role Models & $0.35^{* * *}$ & 0.03 & 1.05 & 0.296 \\
\hline Same-race Role Models & $0.31 * *$ & $0.10^{* *}$ & 3.55 & 0.001 \\
\hline Outdoor Comfort & $0.32 * *$ & $0.15^{* *}$ & 7.36 & 0.001 \\
\hline Religiosity & $0.11 * *$ & -0.02 & -1.02 & 0.310 \\
\hline Moral Objections to Evolution & $0.32 * *$ & $0.41 * *$ & 19.19 & 0.001 \\
\hline Communal Goals & $0.21 * *$ & 0.03 & 1.33 & 0.184 \\
\hline Sense of Belonging in EB & $0.38 * *$ & $0.37 * *$ & 16.69 & 0.001 \\
\hline
\end{tabular}

Table provides information on the Pearson $r$ (zero order) correlation between each predictor variable and interest in evolutionary biology graduate school, standardized regression coefficients, and the test of significance for each regression coefficient. $* p<0.05, * * p<0.001$

same race role models and greater comfort in the outdoors expressed more interest in graduate school in evolutionary biology. Somewhat surprisingly, individuals who had stronger moral objections to evolution reported more interest in graduate school in evolutionary biology. Finally, the comparisons between each of the three ethnic minority groups and Whites were significant even after the additional variables were added to the model.

\subsubsection{Graduate school in ecology}

On Step 1, we entered ethnicity along with the proposed covariates (whether or not students were biology majors, and the number of ecology courses participants had taken), $R^{2}=0.25, F(5,1738)=118.08, p<0.001$. See Table 7. Contrary to Hypothesis $3 \mathrm{~A}$, African Americans expressed more interest in graduate school in ecology as compared to Whites. In addition, Latinos/as also expressed more interest in graduate school than Whites whereas Asians expressed equal interest to Whites. In addition to these ethnic differences, both of the proposed covariates were significant. 
Table 7 Predictors of interest in ecology graduate school

\begin{tabular}{|c|c|c|c|c|}
\hline & $r$ & $\beta$ & $t$ & $p$ \\
\hline \multicolumn{5}{|c|}{ Step 1: $R^{2}=0.25, F(5,1738)=118.08, p<0.001$} \\
\hline African American versus White & $0.11^{* *}$ & $0.11^{* *}$ & 4.60 & 0.001 \\
\hline Latino/a versus White & $0.07 *$ & $0.08^{*}$ & 3.30 & 0.001 \\
\hline Asian versus White & $-0.10 * *$ & $-0.04 * *$ & -1.64 & 0.101 \\
\hline Biology Major & $0.12 * *$ & $0.05 *$ & 2.48 & 0.013 \\
\hline Ecology Courses & $0.48 * *$ & $0.47 * *$ & 22.45 & 0.001 \\
\hline \multicolumn{5}{|c|}{ Step 2: $\Delta \mathrm{R}^{2}=0.23 F(9,1729)=86.74, p<0.001$} \\
\hline African American versus White & $0.11 * *$ & $0.09 *$ & 4.29 & 0.001 \\
\hline Latino/a versus White & $0.07 *$ & $0.10^{*}$ & 4.83 & 0.001 \\
\hline Asian versus White & $-0.10^{* *}$ & 0.04 & 1.71 & 0.087 \\
\hline Biology Major & $0.12 * *$ & $0.04 *$ & 2.41 & 0.016 \\
\hline Ecology Courses & $0.48 * *$ & $0.24 * *$ & 11.75 & 0.001 \\
\hline Knowledge of Evolution & $0.10^{* * *}$ & 0.01 & 0.45 & 0.653 \\
\hline Exposure to Ecology & $0.15 * *$ & -0.01 & -0.48 & 0.629 \\
\hline Role Models & $0.36^{* * *}$ & 0.04 & 1.65 & 0.099 \\
\hline Same-race Role Models & $0.32 * *$ & $0.08 *$ & 2.90 & 0.004 \\
\hline Outdoor Comfort & $0.34 * *$ & $0.14 * *$ & 6.81 & 0.001 \\
\hline Religiosity & $0.18^{* *}$ & 0.003 & 0.15 & 0.878 \\
\hline Moral Objections to Evolution & $0.35^{* *}$ & $0.35 * *$ & 16.84 & 0.001 \\
\hline Communal Goals & $0.24 * *$ & 0.04 & 1.89 & 0.059 \\
\hline Sense of Belonging in Ecology & $0.41 * *$ & $0.33 * *$ & 15.26 & 0.001 \\
\hline
\end{tabular}

Table provides information on the Pearson $r$ (zero order) correlation between each predictor variable and interest in ecology graduate school, standardized regression coefficients, and the test of significance for each regression coefficient. $* p<0.05, * * p<0.001$

On Step 2, we entered all of the proposed challenges to inclusion along with sense of belonging in ecology, $\Delta R^{2}=0.23, F(9,1729)=86.74, p<0.001$. At Step 2, consistent with Hypothesis 3B, sense of belonging in ecology emerged as a strong predictor of interest in graduate school. In addition, several of the challenges to inclusion also related to interest in graduate school in ecology. For example, individuals who reported more same race role models and greater comfort outdoors expressed more interest in graduate school in ecology. In addition, and somewhat surprisingly, individuals who had stronger moral objections to evolution reported more interest in graduate school in ecology. Finally, the comparisons between African Americans and Whites and between Latinos/as and Whites remained significant even after the additional variables were added to the model. 


\section{General discussion}

The goal of the present study was to shed light on factors that may contribute to the underrepresentation of ethnic minorities in EEB, with a particular focus on the most underrepresented group in these fields, African Americans. To accomplish this goal, we tested a theoretical model of how a number of potential challenges to inclusion in EEB could impact students' sense of belonging in EEB and their interest in pursuing graduate school in this discipline. We surveyed a diverse and large group of college-aged African American, Latino/a, Asian, and White undergraduates majoring in STEM in the U.S.

On the whole, we found strong support for several of the hypotheses. Consistent with the first hypothesis, responses to our survey suggest that African Americans experience more potential challenges to inclusion in EEB than Whites. African Americans reported less exposure to ecology, fewer same-race role models, less comfort in outdoor environments, were more religious than Whites, had more moral objections to evolution, and more communal goals. Responses of other ethnic minorities suggest that they experience many of the same challenges to inclusion as African Americans. Latino/a participants reported less knowledge of evolution, fewer same-race role models, less comfort in outdoor environments, more moral objections to evolution, and more communal goals than Whites. Asians reported more misconceptions about evolution, less exposure to role models of any race and less exposure to same race role models than Whites, and less comfort outdoors. However, Asians did not differ from Whites in their religiosity, moral objections to evolution, knowledge of evolution, exposure to ecology, or communal goals.

Consistent with predictions (Hypothesis 2A), African Americans reported a lower sense of belonging in EEB than Whites did even after controlling for a more generalized sense of belonging in college. However, Latinos/as and Asians did not differ from Whites in their feelings of belonging in EEB after controlling for a more generalized sense of belonging in college. This finding suggests that the climate in EEB may be particularly foreign or hostile to African Americans relative to other groups.

In addition to identifying group differences in potential challenges to inclusion and sense of belonging in EEB, we also sought to understand how challenges to inclusion more generally relate to the sense of belonging in EEB. Many, although not all, of the potential challenges to inclusion that we identified were associated with a reduced sense of belonging in EEB (Hypothesis 2B). Knowledge of evolution, exposure to ecology, and feeling comfortable outdoors were all related to having a greater sense of belonging in both ecology and evolutionary biology. On the other hand, being religious and having moral objections to evolution were related to having a lower sense of belonging in evolutionary biology. Thus, challenges to inclusion that are likely the results of access to resources (e.g., knowledge, feeling comfortable outdoors) and challenges that are likely the result of real or perceived 
cultural mismatches between students and EEB faculty (e.g., religion) were both related to feelings of belonging. Moreover, the relationship between challenges to inclusion and sense of belonging remained after statistically controlling for ethnicity.

Two challenges to inclusion in STEM and EEB participation that have been identified in the past, access to same-race role models (e.g., Graves 2019) and communal goals (e.g., Smith et al. 2014), were unrelated to sense of belonging. Although having role models was important to a sense of belonging in EEB, it did not matter if these role models were of the same race. ${ }^{6}$ This finding was particularly surprising and we return to it later. We had also predicted that having communal goals might inhibit feelings of belonging, but this prediction was also not supported. One possibility is that EEB, in comparison to other STEM fields, is more likely to be perceived as affording communal values and goals. When STEM fields are perceived as affording communal goals, then people with communal goals are more attracted to STEM fields (Diekman et al. 2017). The present findings suggest that in STEM fields such as EEB that show atypical patterns of participation in graduate education (e.g., high participation rates of women, low participation rates of ethnic minorities), it may be especially important to examine discipline-specific factors (e.g., comfort outdoors) that may affect feelings of belonging.

We hypothesized that African Americans would report lower interest in attending grad school in EEB than Whites (Hypothesis 3A); however, this hypothesis was not supported. In fact, African Americans and Latinos/as were both more interested in EEB grad school than Whites. Because African Americans and Latinos/as face more challenges to inclusion than Whites, it was surprising that they reported higher levels of interest in graduate school in EEB than Whites. It is possible that ethnic minorities generally have higher educational aspirations compared to Whites and are therefore more interested in graduate school in any field, including evolutionary biology and ecology.

Finally, we hypothesized that the sense of belonging in EEB would predict interest in graduate school in these fields (Hypothesis 3B). Consistent with our predictions, we found that sense of belonging continued to predict interest in graduate school even after controlling for ethnicity, whether or not students were biology majors, the number of EEB courses they had taken, and all of the potential challenges to inclusion that we identified. The results of the current study build on a growing literature demonstrating the importance of feelings of belonging for both members of underrepresented groups and groups that are well-represented (Good et al. 2012; Rattan et al. 2018; Walton and Cohen 2007).

\subsection{Limitations and future directions}

Although the present research sheds light on the factors that may contribute to the underrepresentation of minorities in EEB, there are several limitations that should ideally be addressed in future research. Although we obtained an economically

\footnotetext{
${ }^{6}$ Of note, zero-order correlations between same-race role model and sense of belonging and between communal goals and sense of belonging were significant. These relationships disappeared in the regression analyses.
} 
diverse group of students from all 50 states who attended a wide variety of educational institutions, it was not a random sample. In the future, it would be ideal if researchers were able to obtain representative samples. In addition, future researchers should consider restricting their sample to biology majors. Finally, we were unable to obtain a sufficient sample of Native Americans. Like African Americans, Native Americans are severely underrepresented in EEB and thus studying this group in the future will be extremely important.

In addition to limitations of the present sample, we also had to rely on a selfreport measure of participants' interest in attending graduate school in EEB as opposed to measuring a more behavioral outcome such as applications to graduate school in EEB. Because attitudes and behavior are only moderately correlated (e.g., Ajzen and Fishbein 1977), it will be important for future researchers to study the factors that predict applications to graduate programs in EEB. In the future, longitudinal research that is able to predict both recruitment and retention of ethnic minorities into EEB programs will be of critical importance (e.g., see Merolla and Serpe 2013).

In the present paper, we compared ethnic minority students to White students to test for group differences in challenges to inclusion, sense of belonging, and interest in graduate school. Such comparisons run the risk of essentializing group differences and reinforcing White students as the "normative" group (e.g., see Hegarty and Pratto 2004). We have tried to point out that group differences in representation arise from group differences in access to resources and cultural mismatches between the organizational culture present in EEB and the cultural backgrounds of students, rather than any sort of inherent or biological difference. The fact that challenges to inclusion have a negative impact on belonging, regardless of one's ethnicity, is consistent with this argument. Furthermore, we believe that the solution to group differences in representation lies in making additional resources available, making changes in institutional culture, and in making institutions accountable for inequitable outcomes (e.g., Dowd and Bensimon 2015). Nonetheless, moving beyond a focus on factors that hinder underrepresentation among ethnic minorities to a focus on factors that encourage overrepresentation among Whites may help future researchers to more fully understand group differences in representation.

Finally, it is unclear to what extent the findings in the present research would generalize to ethnic minorities in EEB in countries outside the U.S. We are unaware of the existence of comparable national statistics on the extent to which people of African descent or other ethnic minorities are underrepresented in EEB outside of the U.S. Obtaining cross-country comparative data on minority representation within the sciences is difficult, in part, due to differences in how (and whether) countries collect data on ethnicity (OECD 2006, 2018). Nonetheless, the available research suggests that minority participation varies greatly across fields of science (Elias et al. 2006; Smith and White 2011; Wong 2015). By taking a cross-cultural approach to examining the representation of ethnic minorities in EEB in countries outside the U.S., researchers may be able to gain additional insight into the factors that affect participation. 


\subsection{Implications for efforts to increase minority representation in EEB}

The results of this study suggest several actions that may increase the representation of African Americans and other minorities in graduate education in EEB. For example, involving African Americans, Latinos/as, and Asians in outdoor activities (e.g., hiking and camping) may make more them comfortable in environments where ecologists and evolutionary biologists frequently work and thereby increase these ethnic minority groups' interest in EEB graduate education. African Americans in particular are less likely than Whites to have opportunities to spend time as children engaged in outdoor activities (e.g., Larson et al. 2011). Surveys of visitors and non-visitors to National Parks and National Forests in the U.S. found significantly lower participation of minorities, especially African Americans, in outdoor recreation experience compared to Whites (Cordell et al. 1990; Cordell et al. 2004; Floyd 1998; Krymkowski et al. 2014; Solop et al. 2003; Taylor et al. 2011). Grassroots groups such as Outdoor Afro (https://outdoorafro.com/) seek to increase participation of African Americans in outdoor activities through an approach that combines social media and training others to lead groups of African American on experiences in nature (Meraji 2015). Many agencies of government, such as the National Park Service, are also engaged in efforts to make parks and outdoor experiences accessible, welcoming, and sensitive to the needs of minority visitors (Krymkowski et al. 2014; Taylor et al. 2011).

In addition, cultural differences in religiosity as well as the moral objections to evolution cannot be ignored in efforts to increase URM's sense of belonging in EEB educational contexts (or other science fields that are rooted in evolution). A large proportion of the U.S. population is religious and disbelieves in evolution. AfricanAmericans and Latinos/as are more religious than the U.S. population as a whole and scientists in particular (Pew Research 2009a, b). One method to improve religious students' feelings of belonging in EEB contexts might be teach EEB faculty to navigate conversations around religion (e.g., Graves 2019).

Another way to increase feelings of belonging among ethnic minority students and Whites who come from under resourced schools is to increase knowledge and understanding of evolution. Unfortunately, in-depth courses in evolution are rarely offered in high school and African Americans and Latinos/as are more likely than Whites to be taught science by teachers without a bachelor's degree in science (e.g., Clotfelter et al. 2005). Thus, most students enter college with only vague knowledge of key principles of evolution. Thankfully, effective, online resources for teaching evolution to students of all ages have been developed over the past decade or so (e.g., EVOS, see Wilson 2005). Activities in high schools and MSIs that expose students to this content have the potential to change perceptions about evolution and increase students' interest in learning more about it.

The present finding that role models of any race can increase minorities' sense of belonging in EEB was surprising and contrary to our hypothesis that same-race role models would be critically important to minorities' sense of belonging. Although the results of the present study did not show a unique effect of same-race role models on feelings of belonging, it would be misguided to conclude that same-race role models are unimportant to the experiences of minorities in EEB (Graves 2019). For 
example, same-race role models were related to interest in graduate education in EEB, even after controlling for a host of other variables. Moreover, past research suggests that same-race role models may be more important to some underrepresented minority students than others (Chemers et al. 2011; Syed et al. 2011). Furthermore, increasing the diversity of EEB graduate programs and on the faculties of majority universities may also increase retention of minorities who choose to pursue graduate education in EEB (e.g., Drury et al. 2011) as well as their long-term success. When students see themselves reflected in the composition of faculty, they are inspired to challenge themselves and achieve higher standards of performance (Dee 2005; Hurtado and Alvarado 2013). Despite the specific benefits of same-race role models, the openness to graduate education in EEB expressed by participants and the positive effects of role models from any racial background for ethnic minority participants bodes well for efforts to diversify this field.

\subsection{Conclusion}

Inequity in the inclusion of ethnic minorities relative to Whites in EEB persists despite decades of NSF investment in broadening participation across STEM fields and parallel efforts by EEB professional organizations to increase minority participation (e.g., Ecological Society of America SEEDS Program https://esa.org/seeds /, Society for the Study of Evolution https://www.evolutionsociety.org/, American Institute of Biological Sciences Diversity Programs https://www.aibs.org/diversity/). These efforts to increase the representation of minority groups in EEB stem, in part, from recognition that diversifying EEB is essential to the quality of the science produced within EEB (Armstrong et al. 2007). However, diversifying EEB is also a social justice issue of making career opportunities within the field available to people from all backgrounds.

The present study demonstrated that discipline-specific factors (e.g., comfort outdoors, moral objections to evolution) were critical to understanding challenges to inclusion faced by ethnic minorities in EEB. Moreover, the results suggested that these challenges to inclusion may affect interest in graduate school by reducing students' sense of belonging in EEB. Thus, interventions that target discipline-specific challenges to inclusion in EEB may offer the best chance for success at increasing the participation of ethnic minorities in EEB graduate education and ultimately in the professoriate. Likewise, other STEM disciplines with severe underrepresentation of ethnic minorities may benefit from careful examination of discipline-specific challenges to inclusion that can have downstream consequences for feelings belonging and interest in graduate education.

Acknowledgements This study was supported in part by NSF DEB Grant 1701086 to HLB and LTO. We thank Liv Detrick (Institute for Broadening Participation), Joseph L. Graves Jr. (North Carolina A\&T), Robert Gropp (American Institute of Biological Sciences), Rob Javonillo (Morgan State University), Louise S. Mead and Alexa R. Warwick (Michigan State University), Teresa Mourad (ESA), and Paulette S. Reneau (Florida A \& M University) for help their refining metrics and measures of our survey. We thank India Reidt (Tulane University) for her assistance with preparation of the manuscript. 


\section{Compliance with ethical standards}

Conflict of interest No potential conflict of interest was reported by the authors.

Ethical approval This study was approved by the Institutional Review Board at the author's institution. Data were collected in compliance with APA standards.

Open Access This article is licensed under a Creative Commons Attribution 4.0 International License, which permits use, sharing, adaptation, distribution and reproduction in any medium or format, as long as you give appropriate credit to the original author(s) and the source, provide a link to the Creative Commons licence, and indicate if changes were made. The images or other third party material in this article are included in the article's Creative Commons licence, unless indicated otherwise in a credit line to the material. If material is not included in the article's Creative Commons licence and your intended use is not permitted by statutory regulation or exceeds the permitted use, you will need to obtain permission directly from the copyright holder. To view a copy of this licence, visit http://creativecommons.org/licen ses/by/4.0/.

\section{References}

Ajzen, I., \& Fishbein, M. (1977). Attitude-behavior relations: A theoretical analysis and review of empirical research. Psychological Bulletin, 84(5), 888-918. https://doi.org/10.1037/0033-2909.84.5.888.

Armstrong, M. J., Berkowitz, A. R., Dyer, L. A., \& Taylor, J. (2007). Understanding why underrepresented students pursue ecology careers: A preliminary case study. Frontiers in Ecology and the Environment, 5(8), 415-420. https://doi.org/10.1890/060113.01.

Bailey, G., Han, J., Wright, D., \& Graves, J. (2011). Religiously expressed fatalism and the perceived need for science and scientific process to empower agency. International Journal of Science in Society, 2(3), 55-87.

Bauman, G. L., Bustillos, L. T., Bensimon, E. M., Brown, M. C., \& Bartee, R. (2005). Achieving equitable educational outcomes with all students: The institution's roles and responsibilities. Washington, DC: Association of American Colleges and Universities.

Brown, E. R., Thoman, D. B., Smith, J. L., \& Diekman, A. B. (2015). Closing the communal gap: The importance of communal affordances in science career motivation. Journal of Applied Social Psychology, 45(12), 662-673. https://doi.org/10.1111/jasp.12327.

Chemers, M. M., Zurbriggen, E. L., Syed, M., Goza, B. K., \& Bearman, S. (2011). The role of efficacy and identity in science career commitment among underrepresented minority students. Journal of Social Issues, 67(3), 469-491. https://doi.org/10.1111/j.1540-4560.2011.01710.x.

Cheryan, S., Plaut, V. C., Davies, P. G., \& Steele, C. M. (2009). Ambient belonging: How stereotypical cues impact gender participation in computer science. Journal of Personality and Social Psychology, 97(6), 1045-1060. https://doi.org/10.1037/a0016239.

Clotfelter, C. T., Ladd, H. F., \& Vigdor, J. (2005). Who teaches whom? Race and the distribution of novice teachers. Economics of Education Review, 24, 337-392. https://doi.org/10.1016/j.econedurev .2004.06.008.

College Board. (2014). The 10th annual AP report to the nation. Retrieved August 18th, 2018 from: https ://research.collegeboard.org/programs/ap/data/nation

Cordell, H. K., Bergstrom, J. C., Hartman, L. A., \& English, D. B. (1990). A technical document supporting the 1989 USDA Forest Service RPA assessment. An analysis of the outdoor recreation and wilderness situation in the United States: 1989-2040. General Technical Report-Rocky Mountain Forest and Range Experiment Station, USDA Forest Service, RM-189 (pp. 1-113).

Cordell, H. K., Betz, C., Green, G., Mou, S., Leeworthy, V., Wiley, P., et al. (2004). Outdoor recreation for 21 st century America. State College, PA: Venture Press.

Dasgupta, N. (2011). Ingroup experts and peers as social vaccines who inoculate the self-concept: The stereotype inoculation model. Psychological Inquiry, 22(4), 231-246. https://doi.org/10.1080/10478 40X.2011.607313.

Dawkins, R. (2006). The god delusion. New York, NY: First Mariner Books. 
Dee, T. S. (2005). A teacher like me: Does race, ethnicity, or gender matter? The American Economic Review, 95(2), 158-165. https://doi.org/10.1257/000282805774670446.

Diekman, A. B., Brown, E. R., Johnston, A. M., \& Clark, E. K. (2010). Seeking congruity between goals and roles: A new look at why women opt out of science, technology, engineering, and mathematics careers. Psychological Science, 21(8), 1051-1057. https://doi.org/10.1177/0956797610377342.

Diekman, A. B., Steinberg, M., Brown, E. R., Belanger, A. L., \& Clark, E. K. (2017). A goal congruity model of role entry, engagement, and exit: Understanding communal goal processes in STEM gender gaps. Personality and Social Psychology Review, 21(2), 142-175. https://doi.org/10.1177/10888 68316642141

Dowd, A.C., \& Bensimon, E.M. (2015). Engaging the "race question": Accountability and equity in U.S. higher education. New York, NY: Teachers College, Columbia University Press.

Drury, B. J., Siy, J. O., \& Cheryan, S. (2011). When do female role models benefit women? The importance of differentiating recruitment from retention in STEM. Psychological Inquiry, 22(4), 265-269. https://doi.org/10.1080/1047840X.2011.620935.

Edman, J. L., \& Brazil, B. (2009). Perceptions of campus climate, academic efficacy and academic success among community college students: An ethnic comparison. Social Psychology of Education, 12(3), 371-383.

Elias, P., Jones, P., \& McWhinnie, S. (2006). Representation of ethnic groups in chemistry and physics. A report prepared for The Royal Society of Chemistry and the Institute of Physics. https:// www.iop.org/publications/iop/archive/file_38241.pdf

Floyd, M. F. (1998). Getting beyond marginality and ethnicity: The challenge for race and ethnic studies in leisure research. Journal of Leisure Research, 30(1), 3-22. https://doi.org/10.1080/00222 216.1998.11949816.

Fox, J. (2018, October 11). Newly hired North American tenure track assistant professors of ecology are 59\% women. [Blog post]. Retrieved from: https://dynamicecology.wordpress. com/2018/10/11/newly-hired-n-american-tenure-track-asst-professors-of-ecology-are-59-women -thats-good-news-but-most-ecologists-still-dont-know-it-or-cant-quite-believe-it-now-pleas e-read-the-whole-post/

Fuesting, M. A., Diekman, A. B., \& Hudiburgh, L. (2017). From classroom to career: The unique role of communal processes in predicting interest in STEM careers. Social Psychology of Education, 20(4), 875-896. https://doi.org/10.1007/s11218-017-9398-6.

Gallup. (2016). Most Americans still believe in god. Retrieved August 28, 2018 from: https://news. gallup.com/poll/193271/americans-believe-god.aspx

Gervais, W. M., \& Najle, M. B. (2018). How many atheists are there? Social Psychological and Personality Science, 9(1), 3-10. https://doi.org/10.1177/1948550617707015.

Gilbert, P. N., O’Brien, L. T., Garcia, D. M., \& Marx, D. (2015). Not the sum of its parts: Decomposing implicit academic stereotypes to understand academic outcomes for men and women. Sex Roles, 72, 25-39. https://doi.org/10.1007/s11199-015-0481-1.

Good, C., Rattan, A., \& Dweck, C. S. (2012). Why do women opt out? Sense of belonging and women's representation in mathematics. Journal of Personality and Social Psychology, 102(4), 700717. https://doi.org/10.1037/a0026659.

Graves, J.L. (2019). African Americans in evolutionary science: Where we have been, and what's next. Evolution: Education and Outreach, 12, 18. https://doi.org/10.1186/s12052-019-0110-5

Hawley, P. H., Short, S. D., McCune, L. A., Osman, M. R., \& Little, T. D. (2011). What's the matter with Kansas? The development and confirmation of the Evolutionary Attitudes and Literacy Survey (EALS). Evolution: Education and Outreach, 4(1), 117-132. https://doi.org/10.1007/s1205 2-010-0294-1

Hegarty, P., \& Pratto, F. (2004). The differences that norms make: Empiricism, social constructionism, and the interpretation of group differences. Sex Roles, 50(7-8), 445-453. https://doi.org/10.1023/ B:SERS.0000023065.56633.cb.

Hurtado, S., \& Alvarado, A. R. (2013). Diversity in teaching and learning: Affirming students as empowered learners. Diversity and Democracy, 16(3), 127-155.

Ingersoll, R. M. (2002). The teacher shortage: A case of wrong diagnosis and wrong prescription. NASSP Bulletin, 86(631), 16-31.

Jones, J. M., Dovidio, J. F., \& Vietze, D. L. (2013). The psychology of diversity: Beyond prejudice and racism. Malden: Blackwell Wiley.

Krymkowski, D. H., Manning, R. E., \& Valliere, W. A. (2014). Race, ethnicity, and visitation to national parks in the United States: Tests of the marginality, discrimination, and subculture 
hypotheses with national-level survey data. Journal of Outdoor Recreation and Tourism, 7, 35-43. https://doi.org/10.1016/j.jort.2014.09.008.

Larson, L. R., Green, G. T., \& Cordell, H. K. (2011). Children's time outdoors: Results and implications of the national kids survey. Journal of Park and Recreation Administration, 29(2), 1-22.

Leslie, S. J., Cimpian, A., Meyer, M., \& Freeland, E. (2015). Expectations of brilliance underlie gender distributions across academic disciplines. Science, 347(6219), 262-265. https://doi. org/10.1126/science.1261375.

Marx, D. M., \& Goff, P. A. (2005). Clearing the air: The effect of experimenter race on target's test performance and subjective experience. British Journal of Social Psychology, 44(4), 645-657. https:// doi.org/10.1348/014466604X17948.

Marx, D. M., \& Roman, J. S. (2002). Female role models: Protecting women's math test performance. Personality and Social Psychology Bulletin, 28(9), 1183-1193. https://doi.org/10.1177/0146167202 2812004.

Mead, L. S., Clarke, J. B., Forcino, F., \& Graves, J. L. (2015). Factors influencing minority student decisions to consider a career in evolutionary biology. Evolution: Education and Outreach, 8(1), 6. https ://doi.org/10.1186/s12052-015-0034-7

Meraji, S. M. (2015, July 12). Outdoor Afro: Busting stereotypes that black people don't hike or camp. National Public Radio. Retrieved from: https://www.npr.org/sections/codeswitch/2015/07/12/42153 3481/outdoor-afro-busting-stereotypes-that-blacks-dont-hike-or-camp

Merolla, D. M., \& Serpe, R. T. (2013). STEM enrichment programs and graduate school matriculation: The role of science identity salience. Social Psychology of Education, 16(4), 575-597.

Murphy, M. C., \& Dweck, C. S. (2010). A culture of genius: How an organization's lay theory shapes people's cognition, affect, and behavior. Personality and Social Psychology Bulletin, 36(3), 283-296.

National Science Foundation, National Center for Science and Engineering Statistics. (2015). Science and Engineering Degrees, by Race/Ethnicity of Recipients: 2002-12. Detailed Statistical Tables NSF 15-321, Arlington, VA. https://www.nsf.gov/statistics/2015/nsf15321/.

National Science Foundation, National Center for Science and Engineering Statistics. (2017). Women, Minorities, and Persons with Disabilities in Science and Engineering: 2017. Special Report NSF 17-310. Arlington, VA. www.nsf.gov/statistics/wmpd/.

O’Brien, L. T., Blodorn, A., Adams, G., Garcia, D., \& Hammer, E. (2015). Ethnic variation in genderSTEM stereotypes and STEM participation: An intersectional approach. Cultural Diversity and Ethnic Minority Psychology, 21, 169-180.

O'Brien, L. T., Hitti, A., Schaffer, E., Van Camp, A., Gilbert, P., \& Henry, D. (2017). Improving girls' sense of fit in science: Increasing the impact of role models. Social Psychological and Personality Science, 8, 301-309.

Organisation for Economic Co-operation and Development, Global Science Forum. (2006). Evolution of student interest in science and technology studies: Policy report. https://www.oecd.org/science/ inno/36645825.pdf.

Organisation for Economic Co-operation and Development, Statistics and Data Directorate. (2018). Diversity statistics in the OECD: How do OECD countries collect data on ethnic, racial and indigenous identity? Available at: http://www.oecd.org/officialdocuments/publicdisplaydocumen tpdf $/$ cote $=$ SDD/DOC $(2018) 9 \&$ docLanguage $=$ En.

O'Sullivan, C. Y., \& Grigg, W. S. (2001). Assessing the best: NAEP's 1996 assessment of twelfth-graders taking advanced science courses. Report \#: NCES-2001-451. National Center for Education Statistics (ED), Washington, DC; Educational Testing Service, Washington, DC.

Oyserman, D., Coon, H. M., \& Kemmelmeier, M. (2002). Rethinking individualism and collectivism: Evaluation of theoretical assumptions and meta-analyses. Psychological Bulletin, 128(1), 3-72. https://doi.org/10.1037/0033-2909.128.1.3.

Pew. (2009a). Scientists and belief. Retrieved from: https://www.pewforum.org/2009/11/05/scientists -and-belief/

Pew. (2009b). A religious portrait of African American Life. Retrieved from https://www.pewforum. org/2009/01/30/a-religious-portrait-of-african-americans/\#

Pew. (2018). When Americans say they believe in god, what do they mean? Retrieved from: https://asset s.pewresearch.org/wp-content/uploads/sites/11/2018/04/24152307/Beliefs-about-God-FOR-WEBFULL-REPORT.pdf

Rattan, A., Savani, K., Komarraju, M., Morrison, M. M., Boggs, C., \& Ambady, N. (2018). Meta-lay theories of scientific potential drive underrepresented students' sense of belonging to science, 
technology, engineering, and mathematics (STEM). Journal of Personality and Social Psychology, 115(1), 54-75.

Riegle-Crumb, C., \& Grodsky, E. (2010a). Racial-ethnic differences at the intersection of math coursetaking and achievement. Sociology of Education, 83(3), 248-270.

Riegle-Crumb, C., \& King, B. (2010b). Questioning a white male advantage in STEM: Examining disparities in college major by gender and race/ethnicity. Educational Researcher, 39(9), 656-664.

Rissler, L. J., Duncan, S. I., \& Caruso, N. M. (2014). The relative importance of religion and education on university students' views of evolution in the Deep South and state science standards across the United States. Evolution: Education and Outreach, 7(1), 7-24. https://doi.org/10.1186/s1205 2-014-0024-1

Smith, E., \& White, P. (2011). Who is studying science? The impact of widening participation policies on the social composition of UK undergraduate science programmes. Journal of Education Policy, 26(5), 677-699. https://doi.org/10.1080/02680939.2010.540676.

Smith, J. L., Cech, E., Metz, A., Huntoon, M., \& Moyer, C. (2014). Giving back or giving up: Native American student experiences in science and engineering. Cultural Diversity and Ethnic Minority Psychology, 20(3), 413-429. https://doi.org/10.1037/a0036945.

Solop, F. I., Hagen, K., \& Ostergren, D. (2003). Ethnic and racial diversity of National Park System visitors and non-visitors. NPS Social Science Program, Comprehensive Survey of the American Public, Diversity Report (pp. 1-13).

Stephens, N. M., Fryberg, S. A., Markus, H. R., Johnson, C. S., \& Covarrubias, R. (2012a). Unseen disadvantage: How American universities' focus on independence undermines the academic performance of first-generation college students. Journal of Personality and Social Psychology, 102(6), 1178.

Stephens, N. M., Townsend, S. S., Markus, H. R., \& Phillips, L. T. (2012b). A cultural mismatch: Independent cultural norms produce greater increases in cortisol and more negative emotions among first-generation college students. Journal of Experimental Social Psychology, 48(6), 1389-1393.

Syed, M., Azmitia, M., \& Cooper, C. R. (2011). Identity and academic success among underrepresented ethnic minorities: An interdisciplinary review and integration. Journal of Social Issues, 67(3), 442468. https://doi.org/10.1111/j.1540-4560.2011.01709.x.

Taylor, P. A., Grandjean, B. D., \& Anatchkova, B. (2011). National Park Service comprehensive survey of the American public, 2008-2009: National technical report. Natural Resource Report NPS/NRPC/ SSD/NRR-2011, 295.

Walton, G. M., \& Carr, P. B. (2012). Social belonging and the motivation and intellectual achievement of negatively stereotyped students. In M. Inzlicht \& T. Schmader (Eds.), Stereotype threat: Theory, process, and application (pp. 89-106). New York: Oxford University Press.

Walton, G. M., \& Cohen, G. L. (2007). A question of belonging: Race, social fit, and achievement. Journal of Personality and Social Psychology, 92(1), 82-96. https://doi.org/10.1037/0022-3514.92.1.82.

Walton, G. M., \& Cohen, G. L. (2011). A brief social-belonging intervention improves academic and health outcomes of minority students. Science, 331(6023), 1447-1451. https://doi.org/10.1126/scien ce. 1198364 .

Wilson, D. S. (2005). Evolution for everyone: How to increase acceptance of, interest in, and knowledge about evolution. PLoS Biology, 3(12), e364. https://doi.org/10.1371/journal.pbio.0030364.

Wong, B. (2015). Careers "From" but not "in" science: Why are aspirations to be a scientist challenging for minority ethnic students? Journal of Research in Science Teaching, 52(7), 979-1002. https://doi. org/10.1002/tea.21231.

Young, H. (2005). Secondary education systemic issues: Addressing possible contributors to a leak in the science education pipeline and potential solutions. Journal of Science Education and Technology, 14(2), 205-216. https://doi.org/10.1007/s10956-005-4422-6.

Zhang, G., Anderson, T. J., Ohland, M. W., \& Thorndyke, B. R. (2004). Identifying factors influencing engineering student graduation: A longitudinal and cross-institutional study. Journal of Engineering Education, 93(4), 313-320. https://doi.org/10.1002/j.2168-9830.2004.tb00820.x.

Publisher's Note Springer Nature remains neutral with regard to jurisdictional claims in published maps and institutional affiliations. 
Laurie T. O'Brien is an associate professor in the Department of Psychology at Tulane University. Her current research interests focus on how people make judgments about discrimination and the factors that contribute to the underrepresentation of women and ethnic minorities in STEM fields.

Henry L. Bart, Jr. is a professor in the Department of Ecology and Evolutionary Biology at Tulane University. His field of expertise includes ecology and systematics of freshwater fishes and amphibians.

Donna M. Garcia is a professor in the Department of Psychology at California State University-San Bernardino. Her research focuses on the self-perpetuating nature of social inequality via its effects on human functioning (e.g., motivation, achievement, self-regulation, and psychological and physiological well-being). 